\title{
The novice nursing dean: A qualitative study of the lived experience
}

\author{
Melissa R. Bouws ${ }^{* 1}$, Lori Candela ${ }^{2}$, Jacob Bonnema ${ }^{1}$ \\ ${ }^{1}$ Hope College Department of Nursing, United States \\ ${ }^{2}$ School of Nursing, University of Nevada, Las Vegas, United States
}

Received: November 22, 2015

Accepted: February 24, 2016

Online Published: March 22, 2016

DOI: $10.5430 /$ jnep.v6n8p43

URL: http://dx.doi.org/10.5430/jnep.v6n8p43

\begin{abstract}
Objective: The purpose of this phenomenological study was to describe the essence of the lived experience for those who have recently become first time academic deans of nursing. These deans hold unique leadership positions in academia that influence program direction. Few others have such influence within academia or the profession. Understanding the lived experience of being a novice nursing dean can advance knowledge development on what it is like to be a first time dean as well as provide insight on how to support them in this critical role.

Methods: The research design for this study was interpretive phenomenology. The overarching research question was: What is the lived experience of a novice nursing dean? Seven nursing deans participated in the study, and the technique used to gather data was the recording of face-to-face interviews conducted in a semi-structured format. The interviews were transcribed and manual coding was performed to create themes.

Results: The results yielded four major themes and 11 subthemes. The overarching themes of servant leadership, lack of preparation for the role, the uniqueness of the nursing dean role, and highly political environments inform what a nursing dean experiences within the first three years of their role.

Conclusions: The results of the study revealed an understanding of the complex role of novice nursing deans. The information gathered described how the novice nursing dean is willing to navigate through the challenges of their positions despite a lack of mentorship, the unique demands of nursing education, and the highly political work environments they regularly encounter.
\end{abstract}

Key Words: Phenomenology, Nursing education, Nursing leadership, Professional identity, Role transition, Nursing dean

\section{INTRODUCTION}

Deans of nursing hold a unique position that influences both current nursing practice and the advancement of the profession. Few others have the potential to bring about change within the academic setting or hold such a strong influence on the future of nursing and on our students. In spite of their high visibility and high influence roles, surprisingly little is known about the deans that lead our nation's nursing programs. New deans of nursing are the center of change in academic leadership that provide faculty and stakeholders new vision and focus for a school of nursing. The arrival of a new dean, however, can also be a time of stress. ${ }^{[1]} \operatorname{Redman}^{[2]}$ described barriers faced by nursing deans and determined that strong administrative and leadership skills were needed to handle the challenges of integrating aspects of the role.

Past studies have revealed aspects of the role and what this administrative position entails. ${ }^{[2-5]}$ What is not known is how these deans, particularly deans of nursing; experience this new role. Novice deans are at particular risk for experiencing role ambiguity and role stress because of these challenges

* Correspondence: Melissa R. Bouws; Email: bouws@ hope.edu; Address: Hope College Department of Nursing, United States. 
and the lack of preparation. ${ }^{[3,6]}$ The characteristics of the dean's personal journey are important to understand in order to appreciate what may be needed to successfully transition future novice deans.

\subsection{Literature review}

As this study was about the population of new nursing deans, a literature search was originally undertaken in 2011 and repeated in 2014 for information on the position of the academic dean. The review disclosed what is known about this position, and identified what needed to be studied. The main goal of the literature review was to understand the uniqueness of this role, and to begin to identify central issues for the novice dean experiencing the role for the first time.

The publications were limited by inclusion and exclusion criteria. The search was limited to publications in English, and to dates between 1980 and 2014, as seminal articles of research into deans began being published in the early 1990s. An additional ten years was added to the search to include any research that was done prior to the majority of publications on this subject in the early 1990s. Most articles were excluded on the basis of their content or subject matter to maintain the goal of the review which was to understand the role of dean. The majority of publications focused on the role of dean and what it entails, the concept of leadership as it applies to the dean role, and aspects of interaction with faculty. ${ }^{[5,9-14]}$ The literature presented is a representative sample, included to maintain the goal of understanding the role of dean. Inferences were made about the entire population of articles based on the representative sample described.

A survey study that was done by Musilli-Cerra ${ }^{[7]}$ described the deanship by examining characteristics, functions, and role of nursing deans. The sample included National League of Nursing (NLN) accredited schools, with 306 nursing deans responding to the survey. The survey instrument was intended to collect data about the institution, demographic data, career paths, aspirations, roles and responsibilities, level of satisfaction in the role, and advice to future deans. The results indicated that the majority of the deans were female, tenured, came from a faculty role and planned to stay in the position for less than five years. Their advice to future deans was to develop support networks and to "learn the politics". ${ }^{\text {[7] }}$ Although this research is dated, and the lack of current research is evident, this study was included in the literature review as it revealed demographic information about nursing deans. The lack of retention and longevity with the position is apparent in more recent literature as well. ${ }^{[5,13,14]}$

Del Favero ${ }^{[8]}$ studied the influence of a particular academic discipline and how this affects the relationship with deans and preparation for their role. The sample was 210 deans in research and doctoral institutions in the United States, and used the socialization theory in order to explain how deans experience academic leadership as faculty members and why discipline differences may distinguish their learning. The design was a 128 -item survey study. The findings revealed the importance of deans' reliance on past experiences, previous administrative posts, as well as relationships with faculty leaders as the most highly valued approaches to learning what the dean's job entails. How deans understand their role is very much related to the unique experiences they have previously accumulated as faculty members. As this study used the socialization theory to guide the research, it brings a fresh perspective on the role of dean and how experiences and relationships influence their adaptation to the role.

Wolverton and Gmelch ${ }^{[6]}$ have published multiple studies that describe the deanship, the background and lifestyle of academic deans, and the leadership quality of deans. The publications written from 1998 to 2000 were based on a sample of 1,370 deans of research institutions who completed the 1996 National Survey of Academic Deans in Higher Education. The results of the survey were highlighted through various publications. Some key outcomes were the topics of stress in the dean role, and how institutional and workdefining variables affect stress levels.

The work of Wolverton and Gmelch ${ }^{[3-6]}$ paved the way for future research on deans. They identified how stressful the role can be and what aspects of the role affect their personal and professional life. Another publication by Walter Gmelch ${ }^{[15]}$ utilized the Managerial Stress Model using the same results from the 1996 survey of the same sample of 1370 deans. This particular focus disclosed that the greatest sources of stress are paperwork, meetings, interruptions and workload, which were described as day-to-day irritants that wear away at deans, disabling and distracting them. The study implies that universities must provide for these deans through continued professional leadership development. These studies were done on a large population and did not focus on one discipline such as nursing.

Nursing deans are unlike other deans in various academic disciplines, and warrant further study. It is evident that research on the role of the nurse dean is lacking in the literature. Given the challenges that the novice dean encounters which are unique to nursing such as community clinical partnerships, high cost simulation/lab experiences and low student to clinical teacher ratios, it is essential that their experiences are disclosed. This can be helpful in considering potential strategies to assist future deans to fulfill the role successfully. Vacancies or frequent changes in nursing dean roles can be 
disruptive to the program and set back current initiatives. Retention of these nurse leaders despite the external challenges is critical in order to advance nursing education.

To understand the experiences of novice nursing deans, hermeneutic phenomenology informed by van Manen ${ }^{[16]}$ was utilized for this research study. This method portrays the true nature of the lived experience. This specific phenomenological method incorporates the ontological approach of being in the experience, and utilized interpretations from the researcher's knowledge of the phenomenon. ${ }^{[17]}$ Therefore, this method was ideal for investigating personal transitions such as becoming nursing dean.

\subsection{Purpose of the study}

The purpose of this phenomenological study was to describe the fundamental nature of the lived experience of a novice nursing dean. The justification for this focus was the lack of existing research into this particular position in the academy and the complexity of the role, which is not fully understood from the perspective of a novice nursing dean. There was one broad research question for this study which was "what is the lived experience for novice deans of nursing?" The following questions guided the interviews to elicit information from the participants: a) what has your experience been like since becoming a dean; b) what in your past experience prepared you for transitioning to the role of dean; c) what does a successful transition mean to you as a new dean; d) if you could sum up your experience in a short word or phrase, what would that be?

\section{METHOD}

The specific methodology that guided the data collection, analysis and report writing was interpretive using the phenomenological works of van Manen. ${ }^{[16]}$ The use of phenomenology is a process, a sequence of steps that van Manen describes to investigate an experience. This approach allowed for accurate interpretations of rich data stemming from interviews. Van Manen ${ }^{[16]}$ describes hermeneutic phenomenological research as investigating experiences as we live them, reflecting on essential themes that characterize the phenomenon, describing the phenomenon through the art of writing and rewriting, and maintaining a strong and oriented pedagogical relation to the phenomenon.

To ensure rigor, qualitative credibility measures such as member checking, reflexive validity with audit trails, peer debriefing, and authenticity through verbatim accounts were used as strategies. The research study began with the Institutional Review Board (IRB) approval. Following approval, study recruitment began.

Published by Sciedu Press

\subsection{Sample}

Inclusion criteria for the study encompassed registered nurses who are in the position of nursing dean three years or less and have never held this position before. The participants had the title of University Dean of Nursing, Dean of Nursing, Nursing Dean, or College Dean of Nursing. The rationale for this was because of the difference between a director of a nursing program and a dean. Directors often report to a dean, whether that is a dean of science or another discipline. Deans typically report directly to the provost; illustrating an inherent difference in hierarchy between deans and directors.

Many academic settings, whether research institutions, liberal arts colleges, or community colleges have a position of nursing dean. Maximum variation sampling was used in order not to limit this phenomenon to one type of academic institution. ${ }^{[18]}$ Too little is known about this phenomenon to focus on just one group of nursing deans in one type of academic setting.

A total of seven female nursing deans were interviewed in the Midwest region of the United States. These deans were identified by information gathered through snowball sampling and internet searches for newly appointed deans of nursing. Initial contact was made using their email address listed on the college or university website. Once the interview was scheduled, informed consent was also emailed prior to the interview time for their review. Two deans were from private, not-for-profit universities that had student populations ranging from 2,000 to 5,000. Two deans presided over nursing as well as a college of human services or health professions, working for public universities with a total student body of approximately 11,000. Three deans were employed at associate degree granting institutions; one worked at a private university, while the other two were employed at public institutions with university student populations ranging from 2,000 to 4,000 . The age of the participants ranged from late 30 s to mid-60s. The time of appointment with the participants also varied from six months to two and a half years, as the inclusion criteria was three years or less. The sample size focused on the quality and depth of information obtained from the participants to gain insight into the phenomenon. The number of participants in this study was adequate when saturation of information was achieved and the same ideas and themes began emerging. This was evident after interviewing six deans.

\subsection{Data collection}

The technique used to gather data was recording of faceto-face interviews using a digital recorder. The interviews consisted of a script for the introduction that ensured accurate ethical considerations. Any questions the participant had 
regarding the informed consent were answered prior to the interview and signed consents were obtained prior to starting the recording. The semi-structured interview process enabled the interviewee to talk freely about his/her experience, and openly relay stories. ${ }^{[19]}$ The wording of the questions was open-ended to avoid leading or biased questions. ${ }^{[20]}$

\subsection{Analysis}

All of the interviews were transcribed manually, and essential themes were gleaned out of the interview texts by analyzing recurring ideas in the statements and phrases. These recurrent statements or phrases were termed as "significant statements" which revealed aspects of the lived experience. These statements were highlighted on the transcript text and also written on an index card. Table 1 identifies the overarching themes and subthemes as well as how many times a significant statement was noted in each subtheme. All data written on the index cards were laid out for examination and treated with equal value, or "horizontalized", ${ }^{[18]}$ and then organized into meaningful rows. Each row, which Marshall and Rossman ${ }^{[20]}$ describe as "buckets or baskets", had similar topics. Every index card that contained significant statements was grouped together by theme row and given a "descriptive label". The index cards were then categorized in a small file box, according to their respective descriptive labels.

Afterward, the significant statements and descriptive labels were transcribed into an Excel spreadsheet. Qualitative experts who served as peer reviewers examined the significant statements and descriptive labels and compared them to the content of the interviews. Also, study participants were given the opportunity to review the significant statements and descriptive labels and compare them to the content of their transcribed interviews. This process reflects the methodological rigor of peer debriefing and member checking procedure. The overarching themes and subthemes emerged by factoring in the number of significant statements, their descriptive labels, and categorizing them into overarching and subthemes.

Table 1. Overarching Themes and Subthemes

\begin{tabular}{|c|c|c|c|c|}
\hline $\begin{array}{l}\text { Overarching } \\
\text { Themes }\end{array}$ & Servant Leadership & $\begin{array}{l}\text { Lack of Preparation } \\
\text { for the Role }\end{array}$ & $\begin{array}{l}\text { Uniqueness of the } \\
\text { Nursing Dean Role }\end{array}$ & $\begin{array}{l}\text { Highly Political } \\
\text { Environments }\end{array}$ \\
\hline \multirow{3}{*}{ Subthemes } & $\begin{array}{l}\text { Loss of research or } \\
\text { practice } \\
191 \text { Significant Statements }\end{array}$ & $\begin{array}{l}\text { Actively recruited } \\
117 \text { Significant } \\
\text { Statements }\end{array}$ & $\begin{array}{l}\text { Connecting with others } \\
152 \text { Significant } \\
\text { Statements }\end{array}$ & $\begin{array}{l}\text { "Mean girls" } \\
216 \text { Significant Statements }\end{array}$ \\
\hline & $\begin{array}{l}\text { Lonely position } \\
108 \text { Significant Statements }\end{array}$ & $\begin{array}{l}\text { “The darn budget” } \\
40 \text { Significant } \\
\text { Statements }\end{array}$ & $\begin{array}{l}\text { Faculty shortage } \\
75 \text { Significant Statements }\end{array}$ & $\begin{array}{l}\text { “Big boys win out” } \\
58 \text { Significant Statements }\end{array}$ \\
\hline & $\begin{array}{l}\text { Number of hours } \\
79 \text { Significant Statements }\end{array}$ & $\begin{array}{l}\text { Students' entitlement } \\
58 \text { Significant } \\
\text { Statements }\end{array}$ & $\begin{array}{l}\text { Accreditation process } \\
67 \text { Significant Statements }\end{array}$ & \\
\hline
\end{tabular}

\section{RESULTS}

The interviews yielded four overarching themes and 11 subthemes as labeled in Table 1. These overarching themes included servant leadership, lack of preparation for the role, the uniqueness of the nursing dean role, and highly political environments. Through the participants' stories various subthemes emerged that related to the overarching themes. The subthemes for the overarching theme of servant leadership were loss of research or practice, lonely position, and the number of hours. The theme of lack of preparation included actively recruited, students' entitlement, and "the darn budget" as subthemes. The uniqueness of the nursing dean role had the subthemes of connecting with others, faculty shortage, and accreditation process. Finally, the theme of highly political environments encompassed "mean girls" and "big boys win out" as subthemes. The results led to the development of an original model to explain their relationships.

\subsection{Theme: Servant leadership}

Three of the seven interviewees described their positions as being a "servant to the work" and the other four deans mentioned aspects of being a servant leader. Dean D affirmed this theme as she desired to "help people achieve their highest potential". This overarching theme is pictured in the trunk of the tree, because of the importance of this theme and how it connects to the dean's giving of their time and efforts for the role. These women identify themselves as surrendering to the work of dean. They described what they have sacrificed for the role, including their prioritization of student and faculty development before their own needs, as the role of dean requires a commitment to an institution and a profession, as well as an obligation to faculty and students. This commitment leads to sacrifices particularly with the dean's personal and professional life, as described in the subthemes.

For example, Dean A took the time to investigate how her 
faculty personnel view leadership prior to coming on board as dean. She also described herself as a "servant leader", as other deans mentioned in their interviews.

...my style is a servant leader, so I feel like sometimes I am walking ahead, and sometimes I am walking behind and sometimes beside them... I learned about the wishes of the people, so it was a learning time for me.

There are two things that a new dean needs to know. It is a different role, and you think, 'Oh, I was a great teacher, I want to teach this and teach that,' and you can't. You can't let yourself be loaded down because then you're not there for people who need you, because you're working on this other project.

A part of the overarching theme of servant leadership relates to the ways in which the deans invest a lot of time with their faculty in order to achieve the best outcomes for their students. This was emulated in various points of the interviews, but Dean A stated:

... so I've always had a respect for what the other person's load is, and I put myself as kind of a backup. And, in this situation, I've had to sometimes be kind of a consultant to problem solve, and then put them to work on it, and then be the person who kind of brings them up and works with them.

She went on to say: "... it is my belief that the students can only be as good as the faculty. So unless we are developing the faculty the students can't get better."

... But so, a huge part, here at this college, the dean role in the job description says sixty percent of your time will be developing faculty and I value that statement. I think it's absolutely true, because the more I help faculty develop, then the less I'm involved in their students.

\subsubsection{Subtheme: Loss of research or practice}

These nurse leaders expressed how they either missed practicing as a registered nurse or nurse practitioner, or how they wished they had more time for thinking and writing to further the profession. One dean described her loss with the following statement: "you can't have your foot in both camps; you have to do one or the other." The fact that they did not have time to practice, write, or research was a loss to their identity.

One dean phrased it as “... I'm a nurse practitioner, so [I'm] a very hands-on clinician, and that part of me has been very

Published by Sciedu Press difficult to keep alive. And I hate it. I hate the fact that I can't do it...".

\subsubsection{Subtheme: Lonely position}

As the phrase goes, "it's lonely at the top"; the nursing deans shared that concept in various ways. Some felt they could not converse with their faculty, since they had to "be careful" about what they said.

...Where I felt comfortable sharing pieces...not everything... obviously not everything. .. but where I felt comfortable sharing information with fellow people in my college, uh, this is a different level. This is a very different level, and I have to be careful and have a lot of filters on to sort out what I can or what I cannot share.

... once you transition to that dean level, and you speak, it comes from the mouth of the dean. It doesn't come from me or [a] fellow faculty member. I don't know, it took me a month or two to really realize I have to be careful about how I say what I say and who I say it to.

She also felt there was a distinct difference in how she communicated with others in the clinical setting, in comparison to her communication style as dean. She likened it to the ways in which patients talked with her.

... I can talk to a patient, and they say thank you, and I know they mean it. Instead of OK, what did you mean? What do you need from me? So there's no double talk there... it's genuine, it's authentic, and real, and I don't have to think twice about it.

\subsubsection{Subtheme: Number of hours}

Another aspect of servant leadership of the deanship position was also revealed in the number of hours they work. At times, it is to the expense of their family and personal well-being. Dean F described it as "the number of hours you put in is incredible." Dean D stated that she often does not leave the office until 7:30 or 8:00 at night, and still "carries a bag home, thinking I will do something." Dean G stated that "she works at home constantly." She continued to explain that, in education, as a faculty member, "you can't turn it off", but even in her role now, as dean, she "really can't turn it off." She described how she had a couple days off for other professional requirements, and was overwhelmed with the number of emails that requested her "immediate" response, although she had an "out of the office" automated reply. 


\subsection{Theme: Little preparation for the role}

All nursing deans come from various areas within the healthcare industry and often do not have mentorship or preparation for their roles. Out of the seven participants, six were actively recruited by the provost and faculty. Dean B stated that "a lot of faculty came to me and said, 'you've got to do this," while Dean E was asked on multiple occasions to apply for her position. She said she "was not looking for the job." Many were very content in their previous roles and were not looking for other opportunities. They questioned why they came to the position on occasion. Dean E questioned, "Why, why, why, am I doing this?" The deans felt they were not prepared for different aspects of the dean role, such as the budget, and the current generation of students who surprisingly seemed to have a sense of entitlement.

\subsubsection{Subtheme: Actively recruited}

A majority of interviewees often described how they came to the position by "much coercion". Dean C stated that the "provost asked me to interview for this job, and I'm sitting here thinking... I don't really want it."

With six months to three years of full-time service already completed, some deans began to question why they took the position in the first place, as they did not feel any affirmation of fulfillment within the role. Dean B stated, “... and why am I doing this again?" She led into that question by describing how she had "no clue" what the role entailed:

... I'm thinking, well, I've sort of been there, I sort of know... and, to some extent, I think that's probably true, but I had no clue. I mean, really, the bottom line of the whole thing is that I really, really, had no clue... I really did not have a level of understanding that I thought I did ... and you're going 'and why did I want to do this again?'

... Yeah, because I never came here to do this. Ever. Ever. And if anybody ever asked me if I wanted a deanship, I would tell them they were absolutely nuts... I didn't really want it, I never came here to be the dean... and I look back and I think 'what the hell was I thinking?'

\subsubsection{Subtheme: "The darn budget"}

The fact that deans of nursing also have little preparation for the aspect of economics was conveyed by the participants. The deans expressed their frustration concerning the lack of preparation for that particular aspect of their roles. Dean G stated, "I just now got a handle on the budget." Dean C described it as: "if I could just keep the darn budget in line."

\subsubsection{Subtheme: Students' entitlement}

Another aspect of the position that these nursing deans were not prepared for was the sense of entitlement that nursing students currently have. All of the seven deans mentioned how students in this day and age think nothing of going directly to the dean, or even the university president, for concerns they have about various aspects of the academic life. The deans remarked that they have to teach the students that there is a "chain of command"; many even wonder how students will perform in their future workplace environments.

\subsection{Theme: The uniqueness of the nursing dean role}

The role of nursing dean is not like that of other deans in academia. These deans have particular aspects of their positions that are unique to nursing, and bring additional stressors to the novice. Such aspects include the importance of their community partner relationships, the current faculty shortage that is present nationwide, the intensive accreditation process most colleges of nursing require, and the incorporation of other disciplines in the practice of nursing instruction. Dean D states that the faculty shortage has "all of us deans in positions of feeling strangled right now, that we spend a lot of our time trying to get that accomplished", which reflected the issue of the nurse faculty shortage. The importance of involvement with community partners was reflected in what Dean B stated. She is included in many more projects with the community hospitals, and wants that connection with the college of nursing, as she enjoys being involved in this "other level."

\subsubsection{Subtheme: Connecting with others}

The deans of nursing interviewees stressed how important it was to utilize community connections for clinical placements and collaboration purposes. Dean $\mathrm{C}$ described how the reputation of the nursing school being "clinically proficient" is important for the negotiation of clinical placements and contracts. She stated that it gives the schools credibility when their faculty is clinically active and practicing within the hospitals that their students are placed in.

Dean F takes one day a week to be out of her office on campus, and "out in the community." She stated, "because, in the role of dean, for me, I'm doing a lot of community service things, and it's difficult to do those community service things when you're exhausted with things going down on campus." She believed there was an importance in having a "presence in the community" as a leader in academia. Dean D thought that the "most important thing I can do here is reestablish those community connections."

In the interviews, the majority of the deans relayed how vital it was to establish a network of other nurse administrators in 
order to find support in their new role. One of them described it as "my 'go-to' girls." The deans expressed various ways they connected with others, whether through an established mentor via American Association of Colleges of Nursing (AACN)'s dean mentorship program, an informal mentor at a neighboring school, or even nurse executives at local hospitals and clinical settings. Dean D had a network that she utilized when "I can't bear this group here in nursing."

Dean E desired mentorship, and did not have a network of support at the time of her interview:

... there was no mentoring for me. So that, I think, was the most difficult part. I have sought out, sought out that mentoring from other deans, but... probably the biggest hurdle is the no mentoring, and I kinda feel like, you know, walking in the dark.

Dean $\mathrm{C}$ addressed the lack of mentorship as "there is no one to tell you the job," but she described how she ultimately found her own resources, even without formal mentorship assistance:

... so you have to sort of sort that out on your own. There are resources, you know. AACN has a dean mentorship program; there are other resources around, and, you know, you find your own. We have a group of us that are female deans that get together once a month and kind of commiserate. You have to have that network...

Another aspect of the connection with others is the importance of the deans to be working in partnerships with other departments within the university. Some of the aspects of this subtheme involve the ways in which nursing is viewed by other departments. Dean C designated the collaboration with other disciplines as the future "forward thinking" of nursing. She defined this model of nursing in academia as "this collaborative, social media, sim lab, online, different ways to explore." She also went on to describe how nursing is the one department to try new things.

Unfortunately, sometimes nursing is viewed negatively by other departments within the college or university. A dean from a large university, as well as one dean from an associate degree granting college, stated that other departments viewed them as elitist. Dean D mentioned that the nursing department has a "terrible reputation of elitism."

\subsubsection{Subtheme: Faculty shortage}

Deans in schools of nursing face the challenge of recruiting new nursing faculty, as the majority of nursing faculty are

Published by Sciedu Press presently approaching their retirement years. Dean $\mathrm{C}$ was concerned about the age of the faculty at her institution. She stated that a lot of her faculty are in their 50s or older, and a quarter of them will be retiring within the next three to four years. She went on to say that the nation's nursing faculty, as a whole, is older, and the general sciences have younger faculty in their roles. She felt it was a disadvantage to nursing that the pinnacle age of nursing faculty is in their 60s. She was also concerned about the future of the deanship role in nursing, stating, "A lot of folks will retire, and there is some younger faculty, but none that are able to scoot into the deanship. There needs to be a lot more succession planning." Dean G questioned, as a younger dean, "Where are these new deans going to come from?" She mentioned that she often attended regional meetings in which the average age of fellow deans was 55 to 57 , with some that were even in their 70 s.

\subsubsection{Subtheme: Accreditation process}

Another unique aspect of nursing departments and schools of nursing is the accreditation procedures and processes that are required. Nursing deans in larger universities may have these tasks delegated, depending on the infrastructure of their college of nursing, but the deans that participated in this study were from smaller colleges and universities. Each dean that I interviewed either just completed the accreditation for their department or was in the midst of the process. Dean F stated that "all those accreditation things that I was trying to do meant I had to work at home and on the weekend."

\subsection{Theme: Highly political environments}

The work environments that nursing deans perform in are highly political. Not only do nursing deans have to encounter gender issues, with male versus female academic professional advancement, but they also have to contend with nursing faculty who are resistant to change and seem to have a manner of hostility toward the novice dean. Dean A stated a lot of her role is "all about relationships".

\subsubsection{Subtheme: "Mean girls"}

There is a presence of hostility in the workplace within the profession of nursing. In fact, the phrase that "nurses eat their young" is present in nursing literature. ${ }^{[21]}$ This hostility in the workplace is not only evident with nurses in the clinical setting, but in the academic environment as well. Six of the seven novice dean interviewees mentioned that they received some aspect of hostility from the nursing faculty. The workplace environment was described by Dean D as:

... this is the department who continues to bully each other for so long... who would ever want to work with them?... but I knew that coming in. Taking the job, I said to people, 'do I 
really want to go to work with a group of mean girls?' Nursing should be revered here... not the negative department... when they all get together, they can have their issues.

Dean A also mentioned there is a difference between the older and younger faculty, categorizing the older faculty group as 'nay-sayers'. She also described them as being resistant to new things, as they "won't let things move" and are the "most resistant to any changes" in the department. Dean F stated, "I think that nurses are tough on other nurses sometimes, you know?"

\subsubsection{Subtheme: "Big boys win out"}

The aspect of gender relationships was found in the data, as the deans defined it in their interviews. Dean C described it as "the big boys win out" on a campus university. She was the "token female, and it's like... oh, god." Dean B described how the other deans at her university were all male and the dynamic of "one of the boys".

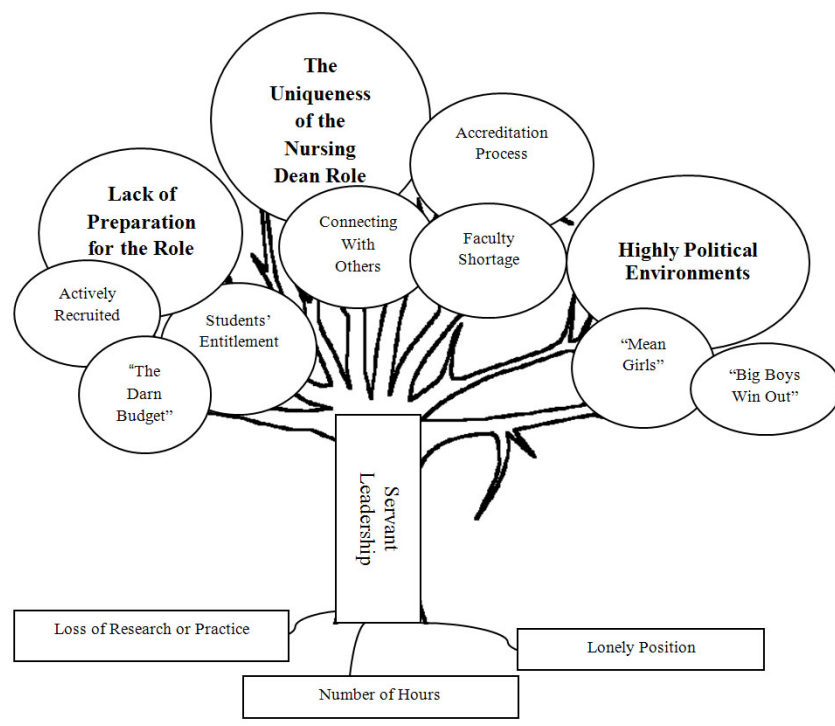

Figure 1. The trunk of the tree illustrates servant leadership, with the roots depicting subthemes. The daily work or role of dean is represented in bold text as the leaves of the tree, while the subthemes are connected to the overarching theme

As these themes as subthemes were described by exemplar quotations, it is helpful to construct a model to portray the experience as a whole. The model depicted in Figure 1 was chosen in order to depict the essence of the lived experience of a novice dean. This model was chosen because a tree is a living growing object, with the center, or trunk, surrounding the theme of sacrifice. The lived experience of a nursing dean is someone who is growing in their position and giving up various aspects of their personal and professional life in order to serve the nursing education. The subthemes of sacrifice are pictured as the roots of the tree. These are subthemes directly related to what they sacrifice, and who they are as a person.

The other themes along with their subthemes are represented as the leaves of the tree. These are concerns that the deans are contending with during this beginner phase, but as the deans grow into the role, they may change.

\section{DiscuSSION}

The results of this phenomenological study draws a significant picture of the role of dean which includes themes such as a lack of mentorship, a difficult workplace environment, stressors of the dean role that are specific to nursing, and a variety of personal and professional sacrifices. The work of Wolverton and Gmelch $^{[3,6]}$ identified how stressful the role can be and how various aspects of the role affect the dean's personal and professional life; and implies that universities must provide for these deans through continued professional leadership development. ${ }^{[15]}$ The various studies that were done by these researchers were on a large population of deans and did not focus on one discipline such as nursing. ${ }^{[3,4,6,15]}$ Nursing deans are unlike other deans in various academic disciplines, and warrant further study. ${ }^{[2,5]}$

Another significant concern, which affects the future of nursing education, also exists - the lack of nurses' willingness to accept academic leadership roles. A majority of deans have actively been recruited, including each of the deans that participated in this study. Nursing in the academic world is at the crossroads between higher education and health. Both of these sectors are male dominated and highly conservative and neither see nursing as a full contributor with regard to most public policy regulation and direction. ${ }^{2]}$ Universities are also patriarchal, and have made little effort to challenge the cultural norm of gender relationships. ${ }^{[2,9-11]}$ Women are less likely to gain tenure, receive recognition for their scholarship, and earn comparable economic rewards. Nursing deans face higher costs of negotiation and often experience exclusion and suppression within the male dominated sector. ${ }^{[2]}$

Nevertheless, certain strategies can still be utilized to enable retention in the deanship role. As this study and previous studies have indicated, there is virtually no mentorship or preparation for the role at this time. The future of the nursing dean position would greatly benefit if current nursing deans used succession planning to prepare and groom potential "next generation" leaders for the position through a variety of leadership training aspects, including mentorship by an experienced nursing dean. ${ }^{[13]}$ 


\section{Conclusion}

In summary, the overarching question for the research investigation was: "what is the lived experience for novice deans of nursing?" The answer to that question lies in the stories that were relayed during each of the seven novice deans' interviews. Novice nursing deans dedicate themselves to further developing their faculty and students, while sacrificing their personal and professional lives. Furthermore, deans are also willing to navigate through each of the challenges of their positions despite a lack of mentorship, the unique demands of nursing education and the highly political work environments they encounter on a regular basis.

As this research study revealed what a lived experience of a novice nursing dean is, it also shed light on the importance of retention and recruitment of nursing deans and the ways in which new deans can enjoy smoother career transitions, particularly through relationship fostering. Similar research should continue so that future nursing professionals will continue to accept academic leadership positions.

\section{ACKNOWLEDGeMENTS}

This research was partially supported by the $\mathrm{PhD}$ Dissertation Award from the University Of Nevada Las Vegas School Of Nursing, and the Sigma Theta Tau Kappa Epsilon Chapter.

\section{CONFLicts OF InTEREST Disclosure}

The authors declare that there is no conflict of interest.

\section{REFERENCES}

[1] Hegyvary S, DeTornyay R. Transitions in the deanship. Journal of Professional Nursing. 1991; 7: 41-4. http://dx.doi.org/10.10 16/8755-7223(91) 90073-T

[2] Redmond G. Life and career pathways of deans in nursing programs. Journal of Professional Nursing. 1991; 7: 228-38. http: //dx.doi.org/10.1016/8755-7223(91) 90032-G

[3] Wolverton W, Wolverton M, Gmelch W. The impact of role conflict and ambiguity on academic deans. Journal of Higher Education. 1999; 70: 80-106. http://dx.doi.org/10.2307/2649119

[4] Wolverton M, Gmelch W, Montez J. The changing nature of the academic deanship: What challenges do deans face? Higher Education Report. 2001; 28: 1-144.

[5] Green A, Ridenour N. Shaping a career trajectory in academic administration: leadership development for the deanship. Journal of Nursing Education. 2004; 42: 489-95.

[6] Wolverton M, Gmelch W. College deans: Leading from within. Westport, CT: American Council on Education/Oryx Press. 2002.

[7] Musilli-Cerra M. A profile of nursing deans: characteristics, roles and functions of deans of NLN accredited colleges and schools of nursing [dissertation]. Athens: Ohio University; 1991.

[8] Del Favero M. An examination of the relationship between academic discipline and cognitive complexity in academic deans' administrative behavior. Research in Higher Education. 2006; 47: 281-315. http://dx.doi.org/10.1007/s11162-005-9389-x

[9] Kenner C, Pressler J. Successfully climbing the academic leadership ladder. Nurse Educator. 2006; 31: 1-3. http://dx.doi.org/10. 1097/00006223-200601000-00001

[10] Kenner C, Pressler J. Barriers to carrying out the dean role. Nurse Educator. 2009; 34: 1-2. PMid:19104332. http://dx.doi.org/1 $0.1097 / 01$. NNE. 0000343409.43728.47

[11] Pressler J, Kenner C. Making the most of the "honeymoon phase" of a deanship. Nurse Educator. 2008; 33: 1-3. http://dx.doi.org/1 $0.1097 / 01$. NNE. $0000299500.32529 .0 d$
[12] Potempa K, Tilden V. Building high-impact science: the dean as innovator. Journal of Nursing Education. 2004; 43: 502-5. PMid:15559775.

[13] Blass T. A Nurse at Heart: The Journeys and Experiences of Nursing School Deans [dissertation]. Long Beach: California State University; 2011.

[14] Quell T. Job Satisfaction in the Role of the Academic Dean in Schools of Nursing [dissertation]. Farmington: University of Connecticut; 2005.

[15] Gmelch W, Wolverton M, Wolverton M, et al. The academic dean: an imperiled species searching for balance. Research in Higher Education. 1999; 40: 717-39. http://dx.doi.org/10.1023/A: 1018717015528

[16] VanManen M. "Doing" phenomenological research and writing: An introduction. Curriculum Praxis Monograph Series: Department of Secondary Education University of Alberta. 1984; 7: 1-28.

[17] Ajjawi R, Higgs J. Using hermeneutic phenomenology to investigate how experienced practitioners learn to communicate clinical reasoning. The Qualitative Report. 2007; 12: 612-38.

[18] Patton M. Qualitative research and evaluation methods. Newbury Park, CA: Sage. 1990.

[19] Polit D, Beck C. Nursing research: generating and assessing evidence for nursing practice. Philadelphia, PA: Lippincott Williams \& Williams. 2008.

[20] Glesne C. Becoming qualitative researchers: An introduction. Boston, MA: Allyn \& Bacon. 2006.

[21] Marshall C, Rossman G. Designing qualitative research. Newbury Park, CA: Sage. 1989.

[22] Goodwin M, Candela L. Outcomes of newly practicing nurses who applied principles of holistic comfort theory during the transition from school to practice: A qualitative study. Nurse Educator Today. 2013; 33: 614-9. PMid:22901371. http://dx.doi.org/10.1016 /j.nedt.2012.07.013 